\title{
An Environmental Value Model to Examine Recycling and Green Development in the Traditional Chinese Medicine Industry
}

\author{
Zhang Haibo ${ }^{1}$, Shen Yuan ${ }^{2, *}$, Shen Junlong ${ }^{1}$, Yuan Pan ${ }^{1}$ \\ ${ }^{1}$ Nanjing University of Chinese Medicine, Nanjing, China \\ ${ }^{2}$ School of Applied Mathematics, Nanjing University of Finance \& Economics, Nanjing, China
}

Email address:

ZHB305@126.com (Zhang Haibo), ocsiban@126.com (Shen Yuan)

${ }^{*}$ Corresponding author

\section{To cite this article:}

Zhang Haibo, Shen Yuan, Shen Junlong, Yuan Pan. An Environmental Value Model to Examine Recycling and Green Development in the Traditional Chinese Medicine Industry. International Journal of Energy and Power Engineering. Vol. 5, No. 2, 2016, pp. 67-72. doi: $10.11648 /$ j.ijepe.20160502.16

Received: March 26, 2016; Accepted: April 28, 2016; Published: May 4, 2016

\begin{abstract}
Green development is a new model of development for China's economy to create a new normal by transforming and upgrading the TCM industry. A green TCM industry must solve the problems of three wastes because wastes generated from processing Chinese medical material (CMM) resources seriously pollutes the ecological environment and puts pressure on the environment. From the environmental value model and green economy theory, this study explains the social value of the environment, clarifies the social costs of TCM resources that create negative externalities from waste generated in the TCM industry. This study on the internal mechanism of external effects and discussion of the green economy model and use of green technology to recycle TCM waste proposes an economic network model to promote the use of technology to reuse TCM waste in a green network of industries.
\end{abstract}

Keywords: Green Development, Environmental Value Model, Waste Reutilization of Tcm, Economic Network Model, Green Technology

\section{Introduction}

Green development represents a social change from traditional agriculture to industry, and finally to an ecological civilization. In 1989, Pierce in the Green Economic Blue Book first proposed the green economy concept, wherein western developed countries experienced eight serious events that shocked the world in the mid-20th century. Since the 21 st century, issues around global warming have become more prominent, and ecological crises, environmental crises, resource crises, and climate crises occur frequently. To cope with the increasing environmental crises, the United Nations (UN) Environment program launched the Global Green New Deal: Policy Brief in October 2008. In 2012, the main theme at the Rio+20 was the "Green economy in the context of sustainable development and poverty eradication," at the same time; the green economy was also the theme of the UN Conference on Sustainable Development.
China's economic development is entering a new normal, and the "Made in China 2025" plan was formulated, the Chinese version of Industry 4.0. Green manufacturing is one of five major projects in the plan, which includes sustainably developing high efficiency, intensity, environmental protection, and resource recycling, all of which can help transform and upgrade China's economy. The Fifth Plenary Session of the Eighteenth Central Committee of the Communist Party of China emphasized, "Achieve the implementation of the '13th Five-Year' planned development goals, firmly establish and effectively implement the innovation, coordination, green, open, shared development philosophy. This is a profound change related to the overall development of our country." This plan intends to address the limitations of the current carrying capacity of China's ecological environment that have become a bottleneck to economic upgrade and transformation. Therefore, the Fifth Plenary Session stated, "to adhere to green development, we 
must adhere to the basic state policy of resource conservation and environmental protection, sustainable development, development of production, affluent lifestyles, and a path to a good society based on ecological development."

Most agricultural waste occurs as litter or is released into the environment at an annual growth rate of approximately $5 \% \sim 10 \%$, which creates significant environmental pollution and squanders resources [1]. TCM waste accounted for a large proportion, especially in manufacturing processes that generate waste residue, waste water, and waste gas caused by the negative external effect of wastes in the industrialization process for TCM resources. Transforming and upgrading the TCM resources industry requires effective governance of these negative externalities. Professor Duan Jinao [2] noted that wastes associated with traditional Chinese medicine have not been used in Chinese traditional medicine production, including waste tissues, unused available substances, waste exhaust gas, waste residue, and waste resources using appropriate methods or techniques to recycle waste or develop available resources from the waste products. This article will focus on Chinese herbal medicine resources in the process of industrialization of waste resource utilization research in the context of traditional Chinese medicine, the industrialization of Chinese traditional medicine resource waste into available or renewable resources, and the negative externalities associated with Chinese medicine wastes to encourage the industry to conserve resources, recycle, protect the ecological environment, the development of green industry. [3]

\section{Model of Ecological Environment Value of TCM Resources}

The World Bank in 1992 listed production capital, social capital, human capital, and ecological environment as the four major types of capital to promote the development of a social economy [4]. The United Nations Environment Programme (UNEP) believes: "the ecological environment under certain conditions can generate economic value, and improvement in ecological environment factors can improve current and future human well-being." Ecological environment value theory is generally based on labor value theory, utility value theory, and existence value theory. Researchers previously only focused on use value rather than non-use value, leading to a global environmental crisis. Since the development of TCM resources that are affected by modern industrial civilization, pharmaceutical processes only extracted the small portion of the chemical composition currently considered useful and discarded the vast majority of chemical substances. The Chinese pharmaceutical manufacturing processes produced three wastes with a serious effect on the ecological environment, the value of which developed along with the value of TCM resources. Figure 1 illustrates the total value model of environmental resources to explain the value of green development of TCM resources. In the figure, Total Economic Value (TEV) is divided into Use Value (UV) or instrumental value and Non-Use Value (NUV), or intrinsic value [5]. UV is divided into Direct Use Value (DUV) and Indirect Use Value (IUV). NUV is divided into Existence Value (EV), Bequest Value (BV), Option Value (OV), and Quasi-Option Value (QOV), though OV and QOV are also sometimes attributed to UV.

The green transition in the TCM industry, compared to the pre-industrial black development that had a "high-efficiency, high pollution" model of development, must move beyond recycling (reduce, reuse, recycle) to promote ecological restoration and environmental improvement as a precondition of development. While the need for sustainable development in the Chinese medicine industry also requires recycling methods, the industry's development must be based on the concept of green development as a new economic norm guided by the green concept, with a green system and green technology as the driving force. This will also mean building a sustainable development model for a green TCM industry, which is feasible based on the characteristics of TCM resources because they include natural resources.

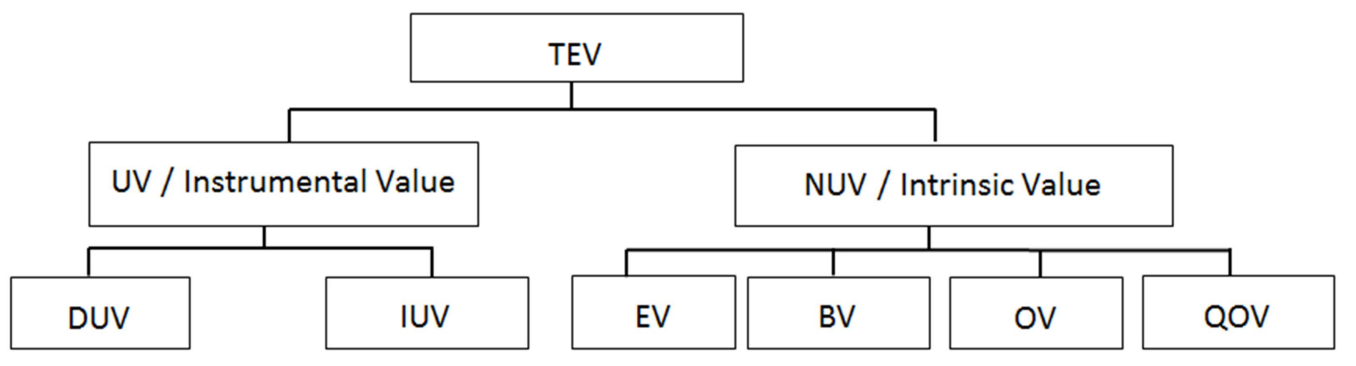

Fig. 1. Total Economic Value (TEV) structural model.

\section{Green Development to Promote TCM Waste Reutilization}

The green economy includes the population, resources, and environmental subsystems that create an organic combination in a social-economic-ecology complex. In this complex, development is not only related to coordinating the interests of people, enterprises, and society, but also the coordination of humans with nature, social development, and ecological environmental protection. The green economy must build a green economic network system using the recycling industry to solve environmental problems. The TCM industry must use 
its resources to transform waste into treasure by formulating a new industry chain to conduct ecological production. We should learn from successful international experiences and adapt this according to the regional situation.

\subsection{The Green Economic Point and the Internal Resource Recycling Mechanism}

The green economic point is the basic level of the green economic network, which is the basic unit or node of the whole network of the green economy focused on green products produced from TCM resources and the transformation of TCM pharmaceutical enterprises based on the Du Pont Company model and the United States Acushnet company model. The DuPont Company model uses the concept of a circular economy in the chemical industry to develop a creative $3 \mathrm{R}$ principle and $3 \mathrm{R}$ manufacturing method. In the production process, the company abandoned some of the chemicals that are harmful to the environment and reduced the use of some chemicals, and found the new technology to recycle waste. By 1994, DuPont reduced plastic waste by $25 \%$ and air pollutants by $70 \%$. The company simultaneously developed methods to recycle waste plastic and chemicals as well as durable ethylene and other new materials.

China can begin with a pilot in a TCM pharmaceutical enterprise. The government encourages enterprises to internally address external problems by means of tax cuts or subsidies to establish circular patterns and mechanisms for a circular enterprise model. Enterprises should adhere to the concept of cleaner production and the principle of "low consumption, low emission, high efficiency" in order to achieve internal material circulation between enterprises, control pollution in the production process, maximize the use of renewable resources, and achieve the purpose of reducing emissions or even emitting zero emissions to protect the environment [6, 7]. For example, waste residues from Chinese herb production can be made into biological fertilizer, biomass carbon (to adsorb cadmium in soil, heavy metals such as lead, and provide general soil improvement) or extract other chemicals, not only reducing the waste of renewable resources and protecting the ecological environment.

\subsection{Green Economy Sheet and Spatial Economic Mechanism}

The green economy sheet makes production in TCM and other related enterprises complementary to centralized production in a certain geographical area to recycle the resources and control pollution. The entire area thus becomes a subsystem of the green economy network. Local governments should establish TCM resources for a regional demonstration of a project focusing on recycling and the three wastes and use a green economic model to protect the ecological environment. We can refer to patterns at the Danish Karen Fort ecological industrial park, which is a typical representative of an ecological system. The park is within a refinery factory, power plant, pharmaceutical factory, and gypsum board factory as the four core factories with other small enterprises which trade using production process, which frequently create by-products and waste, for material and energy exchange and cycling. This has reduced wasted emissions and processing costs, not only significantly upgrades the economy by also greatly improves the ecological environment. Treatment transforms $9 \mathrm{~m}^{3}$ of pharmaceutical factory wastewater into fresh water, reducing water use in refineries by $1.2 \times 10^{6} \mathrm{~m}^{3}$. The refinery will supply gas to the power plant, reducing its annual coal and oil consumption by $3 \times 10^{4} \mathrm{t}$ and $1.9 \times 10^{5} \mathrm{t}$, respectively. Organic residue from the pharmaceutical factory can become organic fertilizer, thus eliminating the need for a landfill. By replacing some of the coal and oil, the reduced sulfur dioxide and carbon dioxide emissions also reduce air pollution [8].

The local government should use the policy mechanism to encourage the establishment of a modern Chinese medicine ecological industrial park in line with the principles of green economic theory and industrial ecology, imitating the natural ecosystem model, similar to the food chain model in industry with a linear economic model of one-way flow from resources to products to change traditional wastes. Enterprises in the park will exchange surplus material, where waste from one business will serve as raw materials for another, thus achieving material interdependence, a closed cycle, multi-level energy use, and ultimately maximize the efficient use of resources and minimize waste emissions. The economy develops while protecting the ecological environment [9]. For example, the TCM GAP cultivation base, Herbal Pieces Processing Enterprises with TCM pharmaceutical enterprises, organic fertilizer manufacturing enterprises, and fine chemicals enterprises will be integrated by design. The waste materials produced in the process of planting and processing Chinese medicinal herbs will be transported for processing and use in the TCM pharmaceutical factory for different products, the waste residue produced by the pharmaceutical enterprises will become inputs in the organic fertilizer production plant, and ultimately supply fertilizer to the Chinese medicine planting base. Chinese medicine waste residue, waste water, and waste gas will supply useful material to the fine chemical enterprise, so that TCM resources are recycled and effectively improve the utilization efficiency in Chinese herbal medicine and make an entire ecological industrial park of green economic firms.

\subsection{Green Economy Line and Supply Chain Management System}

Green economy lines transforms and upgrades the TCM resources industry. By using green technology to optimize the combination of industries to enhance the green connotation of the entire industry, the entire industry becomes a subsystem of a green economic network. Manufacturing is different for Chinese herbal medicine and Western medicine. In Western medicine manufacturing, raw materials are a clear and transparent component, but TCM uses many ingredients, though the exact active ingredients need research and classification. However, despite the importance of the use of 
raw materials in medical manufacturing, the TCM industry should learn from Starbucks supply chain management and the collaborative model of French wine production. Chinese medicine manufacturers must be good at cooperating in terms of cultivation of germplasms, planting, collection processing, preparation technology, and integrating enterprises to form strategic economic cooperation between partners.

\subsection{Green Economy Plane and Recycling-Oriented Social Model}

The green economy plane is in the larger regional and even nationwide TCM resource companies that work with food companies, health care products companies, daily chemical enterprises, and environmental protection enterprises, among others at a deeper level of collaboration. This is a larger area to become a green subsystem. We can refer to the Japanese model. For example, in June 2000, the Japanese government announced the "Promotion of circular society fundamental law" as a basis, and then introduced the "Solid waste management and clean public law" and a policy "Promoting the effective use of resources" as a second-level synthesis. The third aspect relates to the legislative level and industry-specific products. In April 2001, Japan implemented the "Home appliances circulation method," a law stipulating that car manufacturers are obliged to recycle used cars and to recycle waste. At the end of May in the same year, Japan implemented the "Construction of recycling law," a 2005 provision mandating $100 \%$ recycling of construction site waste cement, asphalt, mud, and wood. The third level of legislation also includes "The promotion of container and packaging waste separation law," the "Food recycling law", the "Green purchasing law," and so on. Japan's circular society development model is reflected in the consumer, government, enterprise, social, and many other aspects. Consumers advocate green consumption and encourage consumers to purchase products with environment labels on products to promote green consumption, green production, and thus the development of a green economy. The Japanese government has stepped up publicity efforts to fundamentally change perceptions such that citizens do not despise garbage but rather regard it as a useful resource. Enterprises have been aware of energy conservation due to the scarcity of Chinese resources. In the vigorous development of the eco-industrial creed, an increasing number of enterprises have focused on clean production. According to the circular society concept, production processes are designed to promote recycling of raw materials and energy. The Japanese government urged companies to develop advanced new technology. In product design we should consider the issue of resource reuse. From the social aspect, Japan vigorously developed a green consumer market and promoted the development of industrial resource recycling and utilization.

The long chain of Chinese medical resources waste generated by planting, maintenance, acquisition, rough machining of some waste branches, leaf litter, flowers, fruit, and debris, the government and social organizations should support the establishment of a unified Chinese medicine resource recycling and processing system, using the social circulation model and the mechanism of ecological environment protection, akin to an "arteries, veins, recovery system" nationwide, with full recycling analogous to a venous system in terms of the resources used in Chinese herbal medicine. This will create new value and ensure the full and effective use of renewable resources, promote TCM resource waste recycling in the industry, establish a circular economic industrial chain, and balance economic and ecological development to protect China's environment.

\section{Green Technology and Selection of Waste Reutilization in TCM}

The core of green development is to save resources and protect the environment. Green development in the TCM industry must make full use of high technology to improve the utilization rate of TCM resources and help solve environmental pollution. The TCM industry is the most likely industry for green development because the use of innovative technology to grow the enterprise does not harm the environment and human health in the process of cultivation, production, circulation, and consumption. In the range of the carrying and regenerative capacities of TCM resources under non-reducing conditions, the ecological environment is conducive to healthy choices to balance people and nature through green technology. Green development needs green technology innovation, selection and use of environmentally friendly technologies, to ensure the protection of the ecological environment as the premise of innovative technology and multi-purpose development, maximum efficiency, and recycling of TCM resources.

In the past, due to the lack of scientific research and technical development in the process of harvesting and processing materials related to TCM, the selection of some part of the medicinal material is often used and the remaining non-medicinal parts are discarded. Manufacturing TCM products will produce a significant amount of waste gas, waste liquid, waste residue, and so on $[10,11]$. For example, manufacturers only use angelica root, and discard the stems and leaves. For peonies, firms discard the fibrous root, root head, root bark, etc., thus wasting material. For licorice extract, only the licorice acids are use; the rest is waste, which further wastes resources in Chinese medicine manufacturing. China's medicine industry's average consumption of plant-based medicines for about a year is $7 \times 10^{5} \mathrm{t}$, while producing up to one million tons of residue [12]. This wastes resources and affects the ecological environment. Therefore, the medicine must use the appropriate technology for waste treatment resources, to convert it to available or renewable resources, and improve resource utilization and extend the TCM industrial chain. To save resources and encourage environmentally-friendly development in a circular economy, firms should promote the industrialization of TCM resources and sustainable development, which will lead to good health [13]. 


\subsection{Raw Material Crushing Technology}

Because most TCM wastes are typically solid cellulose material, it forms a relatively stable network structure that is difficult to use fully. Solid wastes thus require preprocessing by steam blasting, crushing, radiation, microwaving, and ultrasonic techniques to deconstruct the organic structure; acid hydrolysis, alkaline hydrolysis, ozone decomposition, ionic liquid with chemical technologies to break the crystalline cellulose structure; and fungi, enzymes, and other biological treatments to degrade the cellulose and lignin. These methods may also have to be used in combination [14]. Biochemical techniques will help transform solid TCM waste for all types of carbohydrates, saccharification to destroy the crystal structure, degrade the cellulosic material so the TCM residue can be used to produce fuel, chemicals, polymers, and other raw materials. The Jiangsu Baoying area is rich in lotus root, and the area has more than 60 lotus root production enterprises. Until the end of 2013 the annual export volume of lotus products was more than $5 * 10^{4} \mathrm{t}$, though this produces a lot of lotus root residue, with only a small fraction used as feed and most abandoned, thus wasting resources. Bao-yu CAI [15] found that crushing technology can degrade hemicellulose and lignin in lotus root residue, undermining its crystallinity to provide a source of dietary fiber. This shows that the techniques will be beneficial to Chinese traditional medicine in terms of recycling and reducing waste, and thus reduce ecological environment pollution.

\subsection{Use of Biomass Energy Development Technology}

From the sustainable development perspective, TCM waste is a clean renewable energy resource, so conserving TCM residue biomass energy to become an important method to industrialize TCM waste resources and create an industrial chain. We can use curing and compression molding and other physical techniques, to transform TCM resource recovery processing of waste stem leaf and residues as fuel directly; by anaerobic fermentation and biochemical technology, transform TCM solid organic waste using bacteria to convert part of the mass to methane, ethanol, and other energy sources; by thermochemical conversion technology to, transform solid wastes into clean solid, liquid, and gaseous fuels, such as of Salvia miltiorrhiza from the waste residue of catalytic pyrolysis to create bio oil [16, 17]. Shangdong BaichuanTongchuang Energy Co.ltd An energy company could use biomass thermos-chemical reaction mechanisms to convert residue into combustible gas or a high quality steam for conversion into electrical energy. These processes help create clean energy, which is both a valuable product but also helps solve issues with fuel shortages and provides an important source of biomass energy development. By August 2014, Shandong BaiChuang built more than 400 biomass gas demonstration projects in 13 provinces and cities.

\subsection{Fermentation Technology}

TCM waste contains many high molecular weight types of organic matter, such as protein, cellulose, and so on. Using fermentation technology can extract a variety of high value-added products. For example, TCM residue fermented with some microorganisms can create biological organic fertilizer and help improve soil via composting technology. Fermentation technology can also convert TCM residue into protein feed for poultry, livestock, and fish. Herbal residues can provide a fermentation substrate for edible fungi and a cultivation matrix for seedlings $[18,19,20]$. The current fermentation technology used in TCM residue conversion to study organic manure exists in a demonstration project run by Guangdong Yili Pharmaceutical Group to develop a "Chinese medicine extraction waste and environmental protection project for the national recycling economy," and addresses key demonstration projects. The project adopts high temperature fermentation technology to transform TCM waste into organic fertilizer, back to the planting base of Chinese medicine, the annual amount will be $1.5 * 10^{5}$ t Chinese medicine waste resources of equal amounts of organic fertilizer matrix, the formation of the cultivation of Chinese Medicine - Chinese medicine extraction - organic fertilizer manufacturing green circular economy industrial chain in the Twelfth Five Year Plan.

\subsection{Extractive Techniques and Enrichment Technology}

TCM residue resource materials are mainly flavonoids, polysaccharides, alkaloids, and triterpenoid glycosides, which can therefore benefit from extraction and enrichment techniques to significantly protect the ecological environment [21]. It is possible to recycle some solid Chinese medicine wastes through a solid-liquid phase equilibrium extraction, chromatographic separation, and enrichment techniques, to extract tanshinone IIA from Salvia miltiorrhiza. Liquid wastes treated with adsorption, membrane filtration, and biological treatment technology not only recycles water resources, but also recovers proteins, polysaccharides, and other TCM ingredients. Gaseous wastes, through condensation, adsorption, and biological purification technology can yield useful resources such as ageratum and mint aromatics[22,23]. The present applications of extraction and enrichment technology are mature in terms of transforming TCM waste. Gegen Ankang City as advantageous resources, and will meet the considerable demand for puerarin, which will generate large amounts of waste liquid containing medically valuable components such as isoflavones, which first squandered Ankang City's resource advantage. Yasuko Yoshiro, a biological resource firm, applies water extraction and membrane separation technology to Pueraria waste to enrich isoflavonesdaidzeinyuan to develop drugs and health foods, extending the chain of Puerarialobata industry development in Ankang City, and thus promoting recycling.

\section{Conclusion}

Green development requires the establishment of a green system, development of a green economic model, and achievement of the "Green New Deal" that has green resource technology innovation at its core. Green technology is 
required to solve the external problems of wastes generated in Chinese medical material (CMM) resource industrialization to promote green technology innovation, protect the environment, and efficiently use TCM resources on the path to green development. It is an effective way for the TCM industry to transform TCM waste into renewable resources, which is one of China's advantages in terms of planting, breeding, quality identification, and extraction and processing technology. TCM waste reutilization is not only conducive to sustainable development and ecological resource protection, but takes full advantage of TCM resources to develop China's TCM industry and promote sustainable development in China's economy.

\section{Acknowledgments}

The study was sponsored by "12th Five-Year" National Science and technology support program (2010BAI04B 03)\& Natural Science in Colleges and universities in Jiang $\mathrm{Su}$ province level project (13KJD110002). We thank Prof Shen yuan for contributions to study design, study coordination; Shen junlong for contributions to study design and study management; Yuan pan for checking the Article's language and style.

\section{References}

[1] Wu Qun. Practical significance and Countermeasures of agricultural waste resource utilization [J]. Modern Economic Research, 2013(10): 50-52.

[2] Duan Jing-ao, Su Shu-lan, Guo Sheng etc. Production of castoff from process in Chinese materia medica resources industrialization as well as resource utilization strategies and modes [J]. Chinese Traditional and Herbal Drugs, 2013, 44(20): 2787-2797.

[3] Wu Xue-Ming, $\mathrm{Xu}$ Ting-Ting, $\mathrm{He}$ Bing-Fang, etc. Establishment of non-aqueous biotransformation system and its application in castoff from Chinese materia medica industrilization $[\mathrm{J}]$. Chinese Traditional and Herbal Drugs, 2015, 46(3): 313-319.

[4] Costanza R.d Arge R.de Groot R. et.al. The value of the world's ecosystem services and natural Capital [J]. Nature, 1997, $387: 1-260$

[5] Davis RK. Recreation planning as an economic problem [J]. Natural Resources Journal, 1963, (3): 239-249.

[6] Pan Dong, Liu Dong-Huang, Tong Qun-Wang. Path Choice of China's industrial enterprises circular economy [J]. Lanzhou Academic Journal, 2014(10): 163-166.

[7] Liu Liang. Learn from the Models of Developed Countries' Circular Economy and Design the Models of China's Circular Economy [D]. Changchun: Northeast Normal University, 2008

[8] Chi Xing-Yun, Research on Mode and Stability Of Regional
Circular Economy [D]. Jinan: Shandong University, 2009.

[9] Zhang Jing-bo. Research on the Resources utilization Modes of Industrial waste Based On Recycling Economy [D]. Hefei. HeFei University of Technology, 2007.

[10] Shi Jian-Yong. Chinese medicine industry economy and development [M]. Shanghai. Shanghai science and Technology Press, 2002.

[11] Yuan Pan, Shen Jun-Long. Causes and optimized strategies of price fluctuations for genuine traditional Chinese medicinal materials [J]. Chinese Traditional and Herbal Drugs, 2014, 45(23): 3503-3508.

[12] Waste extraction of traditional Chinese Medicine can be recycling environmental treatment $[\mathrm{J}]$. Guiding Journal of Traditional Chinese Medicine and Pharmacy, 2012, 18(5): 119.

[13] Duan Jing-ao, Su Shu-lan, Guo Sheng etc. Research practices of conversion efficiency of resources utilization model of castoff from Chinese material medica industrialization [J]. China Journal of Chinese Materia Medica.2013, 40(23): 3991-3996.

[14] Pang F, Xue S L, Yu S S, et al. Effects of combination of steam explosion and microwave irradiation (SE-MI) pretreatment on enzymatic hydrolysis, sugar yields and structural properties of corn stover [J]. Ind Crops Prod, 2013, 42: 402-408.

[15] Cai Bao-Yu, Wang Lei, Tao Guan-Jun, etc. The preparation procedure of fiber in lotus root residue $[\mathrm{J}]$. The Food Industry, 2004(3): 14-15.

[16] Fu Peng. Study on Biomass gasification gas phase product release characteristics and Coke structure evolution behavior, [D].Wu Hang. Huazhong University of Science and Technology, 2010

[17] Wang-Pan, Zhan Si-Hui, Yu Hong-Bing, Study On the catalytic pyrolysis of herb residue for bio-oil, etc. [J]. Environmental Pollution and Control, 2010, 32(5): 14-19.

[18] Wang Jian-Fei, Yu Qun-Ying, Chen Shi-Yong, Environmental hazards of Agricultural organic solid waste and the prospect of composting technology, etc. [J]. Journal of Anhui Agricultural Sciences, 2006, 34(18): 4720-4722.

[19] Huang Xiao-Guang, Qiu Zhe-Shi. Application of Chinese herb residue as feed additive [J]. Guangdong feed, 2007, 16(6): $32-33$.

[20] Wu Yan-Xin, Ji Yan-Xi, Ren Ang, Review of the Research of Edible and Medicinal Fungi Cultivated by Chinese Herbal Medicine Residue [J]. Edible Fungi of China, 2011, 30(4): 3-6.

[21] Duan Jin-Ao. Resources Utilization of Chinese Herbal Medicine Wastes [M]. Beijing, Chemical Industry Press, 2013.

[22] Shi Ling, Hong Hao, Zhang Yan, etc. Separation and purification of tanshinoneÒA from Danshen dregs [J]. Journal of Dalian University of Light Industry, 2010, 29(2): 106-108.

[23] Chen Shi-Lin, The introduction of sustainable utilization of Chinese medicine resources [M]. Beijing, China Medical Science Press, 2006. 